\title{
New frontiers in thermal analysis
}

\section{Stefano Materazzi, Giuseppina Gullifa, Maria Aurora Fabiano, Paola Frati,}

Alessandro Santurro, Matteo Scopetti, Vittorio Fineschi, et al.

\section{Journal of Thermal Analysis and} Calorimetry

An International Forum for Thermal Studies

ISSN 1388-6150

J Therm Anal Calorim

DOI 10.1007/s10973-017-6239-y
ONLINE FlRST

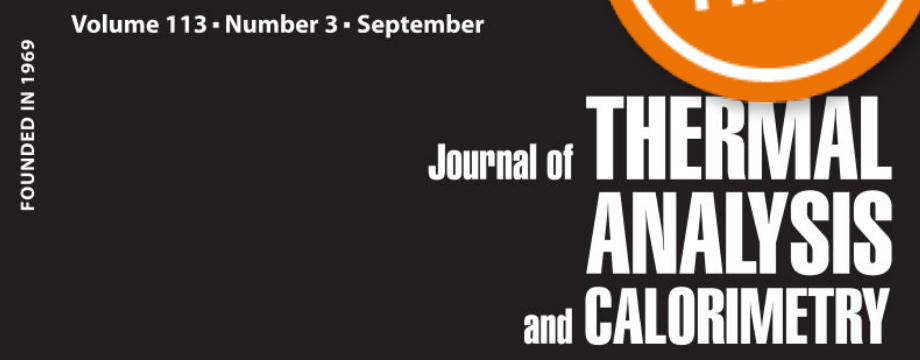

$\begin{array}{lllllllllllll}550 & 600 & 650 & 700 & 750 & 800 & 850 & 900 & 950 & 1000 & 1100 & 1200 & 1300^{\circ} \mathrm{C}\end{array}$

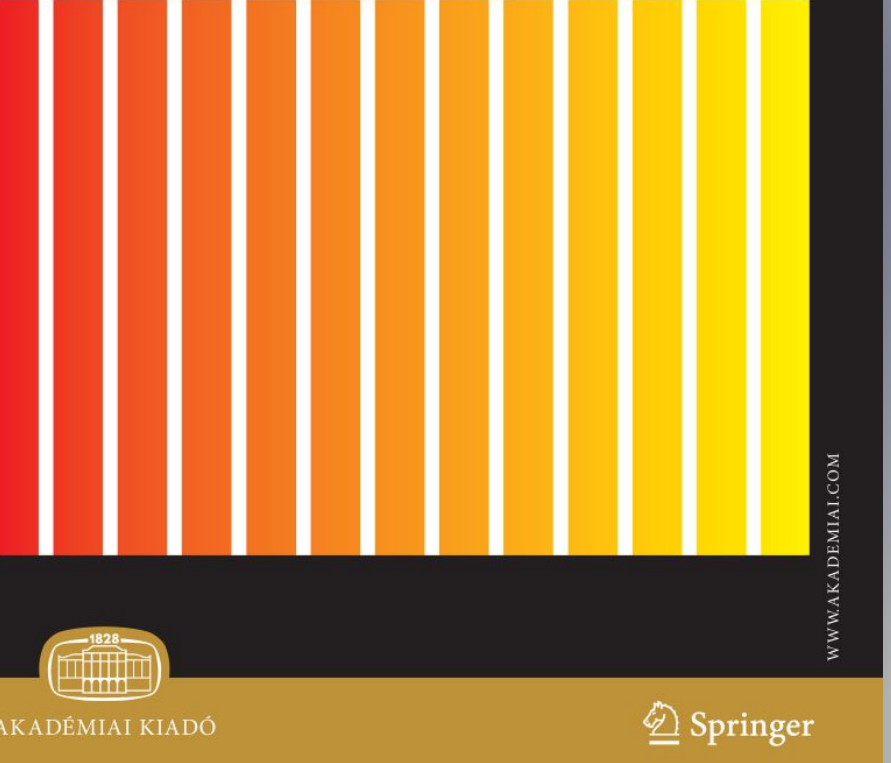

包 Springer 
Your article is protected by copyright and all rights are held exclusively by Akadémiai Kiadó, Budapest, Hungary. This e-offprint is for personal use only and shall not be selfarchived in electronic repositories. If you wish to self-archive your article, please use the accepted manuscript version for posting on your own website. You may further deposit the accepted manuscript version in any repository, provided it is only made publicly available 12 months after official publication or later and provided acknowledgement is given to the original source of publication and a link is inserted to the published article on Springer's website. The link must be accompanied by the following text: "The final publication is available at link.springer.com". 


\title{
New frontiers in thermal analysis
}

\section{A TG/Chemometrics approach for postmortem interval estimation in vitreous humor}

\author{
Stefano Materazzi ${ }^{1} \cdot$ Giuseppina Gullifa $^{1} \cdot$ Maria Aurora Fabiano $^{1} \cdot$ \\ Paola Frati $^{2}$ - Alessandro Santurro ${ }^{2} \cdot$ Matteo Scopetti $^{2} \cdot$ Vittorio Fineschi $^{2}$. \\ Roberta Risoluti ${ }^{1}$
}

Received: 14 December 2016/ Accepted: 22 February 2017

(C) Akadémiai Kiadó, Budapest, Hungary 2017

\begin{abstract}
The coupling of thermogravimetric analysis (TG) associated with chemometrics is proposed as an innovative approach in thanatochemistry in order to develop a new analytical tool using thermal analysis for the characterization of vitreous humor. Vitreous samples were selected from the medicolegal deaths which occurred in casualty and where the death interval is known. Only hospital deaths with no metabolic disorders were taken, and the precise time of death was certified by the treating physician. Samples were analyzed by TG7 thermobalance, and principal component analysis was used to evaluate the results. The TG/Chemometrics outcomes show a clearly distinct behavior according to the postmortem interval, concluding that TG and Chemometrics are capable of predicting the time since death using only a few microliters of vitreous, without any pretreatment and with an hour of analysis time.
\end{abstract}

Keywords Vitreous humor - Thermogravimetry · Chemometrics · Forensic sciences

\section{Introduction}

Thermogravimetry coupled with chemometrics (TG/Chemometrics) proved to be a rapid and cost-effective tool for the analysis of complex biological matrices [1]. The

Roberta Risoluti

roberta.risoluti@uniroma1.it

1 Department of Chemistry, "Sapienza", University of Rome, p.le A.Moro 5, 00185 Rome, Italy

2 Department of Anatomical, Histological, Forensic Medicine and Orthopaedic Sciences, "Sapienza", University of Rome, p.le A.Moro 5, 00185 Rome, Italy coupling TG/Chemometrics is emerging as a novel approach, consisting of a multiparametric statistical analysis of thermogravimetric curves, thus allows the identification of significant differences in the thermal profile of the investigated sample. In some cases, little sample-to-sample differences can cause very small differences in thermogravimetric profile. This means that the resulting TG data obtained depends on more than one variable simultaneously and thus is multivariate. To this end, chemometric approach based on multivariate analysis becomes very useful.

Thermogravimetry has been successfully applied to very different matrices [2-12] since no sample pretreatment is needed. Consequently, the information reflects the true composition and all the possible interactions due to the complexity of the specific matrix investigated, because nothing affects the results. These advantages are enhanced when a complex matrix is under investigation: The whole, original sample is directly inserted in the sample crucible and immediately analyzed. As the matrix increases its complexity (biological specimens), a simultaneous evaluation and monitoring of a great number of factors for its characterization are required. The main criterion in this situation is to build up the initial analytical model as robust as possible in order to ensure predictive results.

Such an aim may be achieved in analytical chemistry by chemometric tools $[13,14]$. Food chemistry problems and the relationships between food composition and sensory evaluation, food processing and storage, production, climate, and physical characteristics frequently require the use of chemometric techniques and strategies [15].

For this reason, the coupling TG/Chemometrics is considered to study correlations between thermogravimetric profiles and develop a model of prediction not affected by the specific complexity of the matrix under investigation. In particular, the objective of this study is to introduce TG 
coupled with a chemometric approach as a useful strategy for the postmortem investigation of vitreous humor with the aim of estimating the interval since death.

Postmortem interval (PMI) is defined as the time elapsed between death and the time of autopsy and is largely used in thanatochemistry to support forensic investigations. Although the interpretation of various changes occurring after death provide useful information, the exact time of death can be rarely estimated on the basis of autopsy findings alone, thus the appropriate range of PMI must be deducted.

Among the commonly investigated biological matrices, blood, cerebrospinal fluid, and synovial fluid show postmortem alterations in the levels of their electrolytes. These modifications progressively increased until putrefaction and can help forensic pathologist in estimating PMI [16, 17]. Beside conventional body specimens, vitreous humor is of growing interest [18-22] in forensic chemistry as a stable fluid in the postmortem period. In addition, vitreous humor is located in closed compartments thus, hardly contaminated even in the late postmortem interval [23]. As a consequence, the isolated topography and the resistance to microbiological contamination result in a well-protected and easy to collect specimen and make vitreous humor a very suitable medium for postmortem investigations. Additionally, in vitreous humor, chemical changes occur at a slow rate, extending the period of time during which it may be used for PMI estimation purposes [24].

A number of two-exponential formula have been proposed by Marshall and Hoare for PMI estimation based on supravital reactions, postmortem lividity, and rigor mortis [25-27]. In addition, the literature provides several chemical approaches for estimating the time since death but officially recognized methods are lacking in forensic community [27-29].

Nowadays, it is widely accepted that the potassium concentrations [18, 19, 30-32] and hypoxanthine [22, 24, 33-37] in the vitreous humor contribute in estimating the time of death within a recent time interval.

Alternative analytical techniques were recently considered in determining important modifications of chemical components of such as optical fluorescence [38] and highresolution NMR techniques [39].

Moreover, amino acid and organic acid concentrations, as well as lipid analysis, are of great importance in forensic sciences and could be good predictors of the time since death. Instrumental methods, applied with or without chemical pretreatments, have been developed to identify, characterize, and quantify organic metabolites as a help for PMI determination [40]. Finally, instrumental detection of racemization and/or functionalization is techniques often used to assess any variation of amino acids [41-44].

Despite all the advances made in this field, it is well recognized a lack in standardization of methodologies as well as instrumentations that may lead to obtaining different potassium concentrations, thus a different estimation of the correct PMI.

To this end, the feasibility of TG/Chemometrics approach based on Principal Components Analysis (PCA) was investigated and a comprehensive analytical tool was develop to enhance correlation between thermogravimetric profiles. The proposed model was applied to process unknown samples and permitted a correct identification of the correct PMI.

\section{Experimental}

\section{Humor samples}

Vitreous was collected from right and left eyes separately using a sterilized 20 gauge hypodermic needle in order to estimate differences in the thermogravimetric profile and at least, to consider a pool of the two eyes for the thermogravimetric analysis. Around $2 \mathrm{~mL}$ of vitreous humor was aspirated through a scleral puncture on the lateral canthus of each eye and a clear fluid was obtained and directly analyzed; the contaminated samples with tissue fragments were discarded. After drawing the vitreous humor, $2 \mathrm{~mL}$ of normal saline was injected in each eye for cosmetic restoration of eyeball. The collected samples were stored at $4{ }^{\circ} \mathrm{C}$ prior to the thermogravimetric analysis.

\section{Thermogravimetry}

Samples were analyzed by a PerkinElmer TGA7 Thermobalance (Massachusetts, USA). Vitreous humor $(30 \mu \mathrm{L})$ was placed into the crucible, and temperature was measured using a thermocouple directly attached to the crucible. The temperature was raised from 20 to $800{ }^{\circ} \mathrm{C}$, with a $10{ }^{\circ} \mathrm{C} \mathrm{min}^{-1}$ heating rate, as the best resolution rate. The carrier gas (air flow) was maintained at a $100 \mathrm{~mL} \mathrm{~min}^{-1}$ flow rate. To ensure an accurate measurement of the sample temperature, the calibration of the temperature was performed using the Curie-point transition of standard metals, as specified by the equipment recommendations. Each sample was analyzed in triplicate, and a high reproducibility of the resulting curves was observed. Derivative thermogravimetric data (DTG) were also calculated to compare samples and represent the derivative of the function $\mathrm{TG}(\mathrm{T})$ with respect $\mathrm{T}$.

\section{Chemometrics}

Thermogravimetry has been scarcely considered in the existing literature for the study of biological matrices, and a thermal approach has not been done yet for the study of 


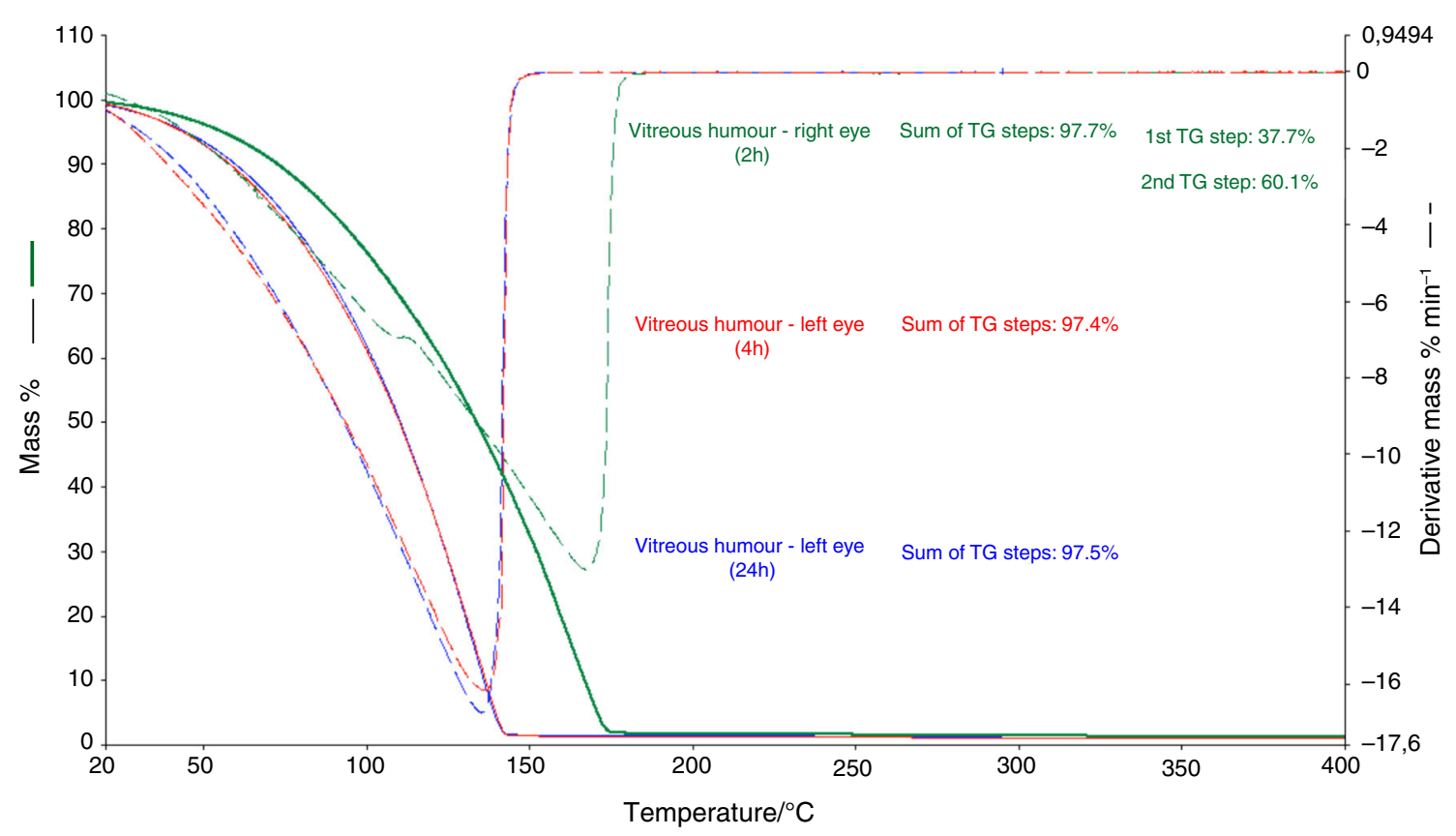

Fig. 1 TG and DTG curves of a sample collected and directly analyzed within $2 \mathrm{~h}$ (right eye) and after 4 and $24 \mathrm{~h}$ (left eye)

vitreous humor. To this end, a simple exploratory tools were only considered in evaluating and comparing the results, as the aim of this study was to develop a new method that provides useful information directly and rapidly, with a minimum of experimental and data processing effort. The processing data from thermogravimetric curves were pretreated, and PCA [45, 46] was used as the display method in order to identify directions in the dataset with higher variability. To remove, or at least, to minimize any unwanted sources of variability on the curves, the effect of a number of mathematical pretreatments was investigated: In particular, Standard Normal Variate transform [47], Column Autoscaling, and Mean-centering [48, 49] preceded by first or second derivatives. From these, the Column Autoscaling was selected, as it provided the best performing conditions of separation for vitreous samples according to PMI. Diagnostics and acquisition of the thermogravimetric data were carried out by Pyris software (Thermo Fisher Scientific Inc., Waltham, MA, USA) as ASCII files, which were then imported into V-PARVUS 2009 package [50].

\section{Experimental}

Postmortem samples from 24 individuals (12 males and 8 females, mean age $61 \pm 19$ years) were collected during forensic autopsies at the Institute of Forensic Medicine of Sapienza University of Rome. Autopsies were included in the study as routinely, selecting cases with a documented PMI as reference samples to define the chemometric model. Moreover, four subjects with undefined PMI were also analyzed in order to verify the approach. Once the model is built, it can be used to predict unknown samples.

\section{Results and discussion}

\section{TG data}

Preliminarily, a typical thermogravimetric behavior of vitreous humor specimen was defined as a result of thermally induced decomposition in the range $20-800{ }^{\circ} \mathrm{C}$. Samples from each eye were analyzed separately, in order to estimate the characteristic thermogravimetric profile of right and left vitreous and no significant differences were observed. Nevertheless, since the aim of this study is to develop a model of prediction for postmortem interval in forensic investigations, a pool of the two vitreous was considered in order to build a model as robust as possible to be used in all the cases, thus not eye-dependent.

Two main releasing steps can be described: The first, is related to the loss of water (the main component of vitreous, $97.8 \pm 0.5 \%$ ), while the second decomposition process is associated with residue of metal oxides remaining at high temperatures $(1.0 \pm 0.4 \%)$. In some cases, the first derivative curve of the TG (DTG) demonstrated the presence of overlapped processes in the first releasing step and permitted to identificate the bulk and bound water contribution, thus to calculate the bulk/bound water ratio. This is particularly useful in biological matrices where cells and 

storage conditions on the reproducibility for sample 19
Fig. 2 Evaluation of the
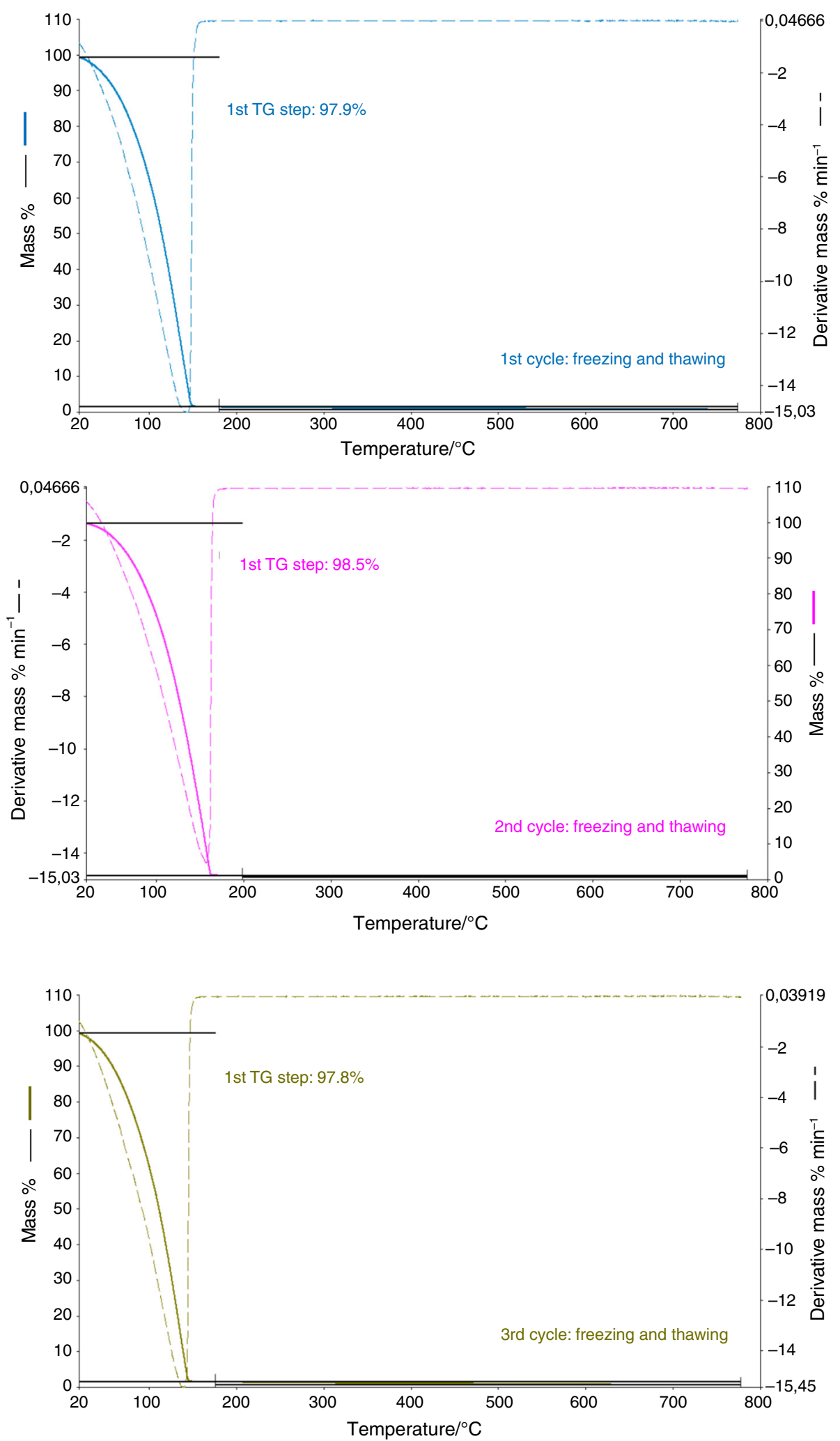

tissues are involved in maintaining the homeostasis. Nevertheless, a first important evidence of postmortem modifications is related to the loss of the bulk water contribution within $2 \mathrm{~h}$. The achieved TG and DTG curves [derivatives of the function TG $(\mathrm{T})$ with respect of T] of samples with a PMI ranging from 0 to $4 \mathrm{~h}$ demonstrated the presence of the two overlapped processes only for those subjects where vitreous was collected before $2 \mathrm{~h}$ since death and directly 
Table 1 Description of vitreous humor samples and calculated water percent

\begin{tabular}{|c|c|c|c|c|}
\hline Case no. & Age/years & Gender & PMI/days & 1st TG step $20-200{ }^{\circ} \mathrm{C} / \%$ \\
\hline 1 & 85 & M & 2 & $97.7 \pm 0.4$ \\
\hline 2 & 82 & M & 2 & $97.8 \pm 0.3$ \\
\hline 3 & 84 & $\mathrm{~F}$ & 5 & $97.6 \pm 0.6$ \\
\hline 4 & 87 & $\mathrm{~F}$ & 5 & $97.6 \pm 0.2$ \\
\hline 5 & 32 & $\mathrm{~F}$ & 0 & $98.2 \pm 0.5$ \\
\hline 6 & 63 & M & 3 & $97.4 \pm 0.3$ \\
\hline 7 & 65 & M & 3 & $97.4 \pm 0.5$ \\
\hline 8 & 45 & M & 5 & $96.7 \pm 0.2$ \\
\hline 9 & 47 & M & 5 & $96.7 \pm 0.7$ \\
\hline 10 & 78 & M & 3 & $98.1 \pm 0.4$ \\
\hline 11 & 75 & M & 3 & $98.1 \pm 0.4$ \\
\hline 12 & 36 & $\mathrm{~F}$ & 2 & $98.4 \pm 0.3$ \\
\hline 13 & 39 & $\mathrm{~F}$ & 2 & $98.4 \pm 0.6$ \\
\hline 14 & 78 & M & 15 & $97.3 \pm 0.6$ \\
\hline 15 & 74 & M & 15 & $97.4 \pm 0.3$ \\
\hline 16 & 60 & M & 3 & $97.3 \pm 0.4$ \\
\hline 17 & 32 & M & 0 & $98.4 \pm 0.2$ \\
\hline 18 & 56 & $\mathrm{~F}$ & 0 & $98.6 \pm 0.7$ \\
\hline 19 & 54 & $\mathrm{~F}$ & 15 & $98.1 \pm 0.3$ \\
\hline 20 & 49 & $\mathrm{~F}$ & 15 & $98.2 \pm 0.5$ \\
\hline
\end{tabular}

Values are expressed as mean \pm standard deviation and range

analyzed (no refrigerated storage conditions were adopted). As the time since death increases, the two processes change into one step. To verify this behavior, vitreous collected from the two eye of the same subject immediately after death, were analyzed over a period of $24 \mathrm{~h}$ under different conditions: The right eye was analyzed and stored at $-20{ }^{\circ} \mathrm{C}$ for reproducibility evaluation, while the left one was maintained in not refrigerated conditions, in order to simulate such situation where vitreous collection occurred after $2 \mathrm{~h}$ since death. An example of a TG profile from the same subject within $24 \mathrm{~h}$ is reported in Fig. 1. In addition, the effect of the heating rate was investigated and three conditions were considered $\left(5,10\right.$ and $\left.20{ }^{\circ} \mathrm{C} \mathrm{min}{ }^{-1}\right)$ concluding that the best resolution was achieved when a scanning rate of $10{ }^{\circ} \mathrm{C} \mathrm{min}{ }^{-1}$ was selected, as it provides the identification of the two processes related to the bulk and bound water release, within $2 \mathrm{~h}$.

In order to provide a correct sampling protocol prior to TG analysis, the effect of vitreous storage after collection was investigated. Samples were analyzed at varying storage conditions and times and subjected to three cycles of freezing $\left(-20^{\circ} \mathrm{C}\right)$ and thawing (room temperature). In the tested conditions, no statistically significant variations ( $p$ value of 0.37 ) have been detected: In all the cases, the percentage of water content was found to be within the interday precision. In Fig. 2, an example of the stability investigation is reported for sample 19 and the average water amount was estimated $(98.1 \pm 0.3 \%)$. In conclusion, for a correct analytical protocol, samples were storage immediately after sampling $\left(-20^{\circ} \mathrm{C}\right)$ and then analyzed in triplicate.

The thermally induced decomposition of all the analyzed samples is reported in Table 1, and in Fig. 3 the TG and DTG profiles of all the analyzed vitreous humor according to the optimized protocol are overlapped. The acquired thermogravimetric showed that no significant statistically differences seem to be diagnostic to PMI identification and a correlation between the time since death and DTG can be observed. To overcome these problems, chemometric tools were considered for interpreting results. The main role of chemometrics data processing is to eliminate the problems caused by data overlapping between components, enabling their simultaneous determination with no sample pretreatment. For this reason, data reduction techniques such as exploratory Principal Components Analysis (PCA) were selected and the acquired thermogravimetric curves were imported into a chemometric package in order to verify correlation among samples and to build a model of prediction of PMI.

For the dataset construction, the acquired TG curves were considered in the range between 20 and $800{ }^{\circ} \mathrm{C}$ and mathematically pretreated. As far as the data are 

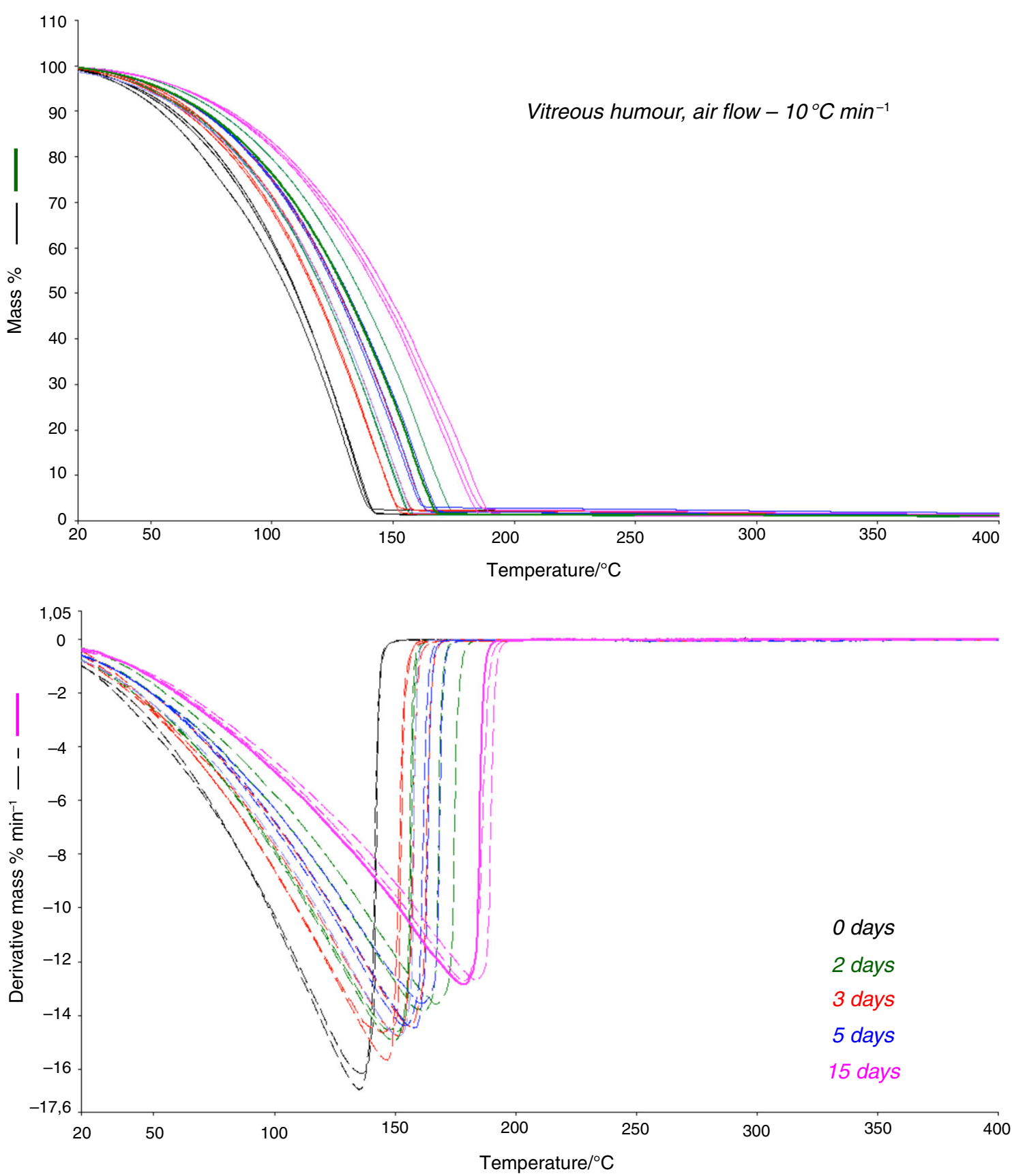

Fig. 3 TG and DTG curves of all the analyzed samples

concerned, among the investigated pretreatments the Column Autoscaling results in optimal discrimination ability and was consequently considered for data processing. The chemometric evaluation gave rise to a plot in which every point represents a different sample. The exploratory analysis of all the thermogravimetric data using PCA (Fig. 4) shows a clear discrimination based on the components PC1 and $\mathrm{PC} 2$, which explain, respectively, the 61.26 and the $34.50 \%$ of the total variance, and individuates distinct group of samples belonging to different PMI.
The interpretation of the scores plot provides several important results: A good correlation among subjects belonging to the same class (same PMI) could be observed, resulting in a different location of samples in the plot. The location of samples also suggests that PC1 distinguish the investigated samples according to the time since death, concluding that the thermogravimetric analysis has the ability to identify different PMI when all the thermally induced processes (e.g., the entire TG curve) were considered. In addition, the chemometric investigation of the 
Fig. 4 Scores plot from PCA for the thermogravimetric data of vitreous humor
Fig. 5 Resulting scores plot of unknown samples from TG/ Chemometrics approach
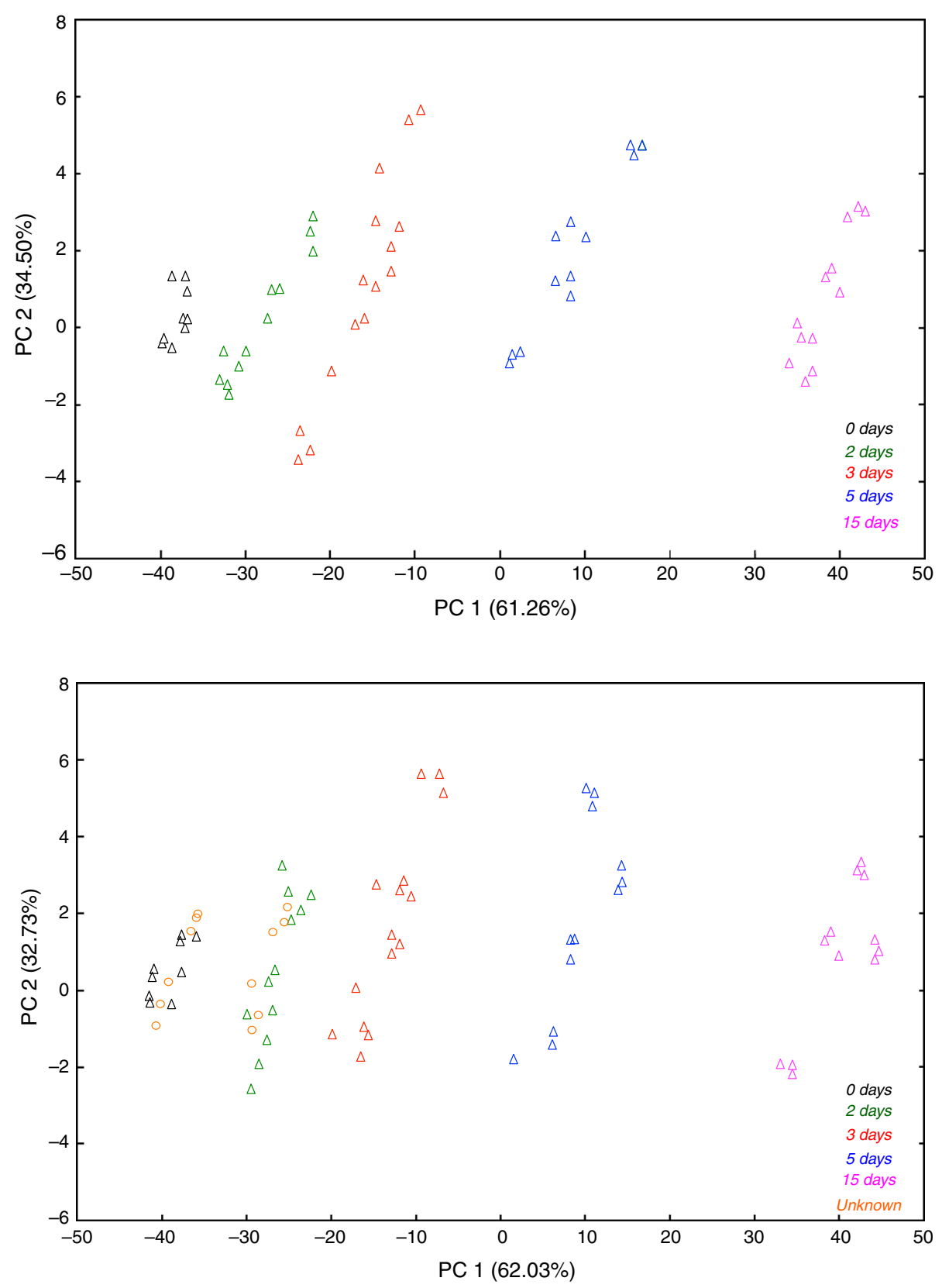

factor loadings demonstrated a relevant contribution of the interval $300-800{ }^{\circ} \mathrm{C}$ for the discrimination of samples according to PMI. The obtained results confirm the significant role of chemometrics in thermogravimetric data interpretation.

The developed model was consequently used to process four unknown samples in order to test the prediction ability of the model. TG curves were recorded as previously described, and PCA was carried out in the optimized conditions obtaining a plot in which the first two components (overall explained variance 94.76\%) permitted to correlate the unknown samples as belonging to the group of a specific PMI, according to the similarity with reference samples. Figure 5 shows a new plot in which all the investigated samples were processed simultaneously and confirming the ability of this model to early predict the time since death. As shown results from medicolegal autopsy were in agreement with those obtained by TG/ Chemometrics approach.

\section{Conclusions}

This study introduces a novel approach to vitreous humor for postmortem evaluation of the time since death. The method consists of a thermogravimetric analysis followed 
by a chemometric evaluation of the acquired data that requires few microliters of sample, without any pretreatments. In addition, a comprehensive analytical protocol for vitreous (from sampling to storage) was developed on the basis of the TG behavior of this specimen with the aim of determining the correct post mortem interval (PMI).

The association of chemometric tools to TG permitted a quick identification of little differences in the TG curves and demonstrated the capability of estimating postmortem interval (PMI) in vitreous humor. The parallel medicolegal outcomes from autopsies, confirmed the obtained results allowing to correctly predict the PMI in unknown sample and suggesting to consider the approach TG/Chemometric as a promising tool for PMI estimation in forensic cases.

\section{References}

1. Risoluti R, Materazzi S, Sorrentino F, Maffei L, Caprari P. Thermogravimetric analysis coupled with chemometrics as a powerful predictive tool for $\beta$-thalassemia screening. Talanta. 2016;159:425-32.

2. Materazzi S, Vecchio S. Recent applications of evolved gas analysis by infrared spectroscopy (IR-EGA). Appl Spectrosc Rev. 2013;48:654-89.

3. Materazzi S, Risoluti R. Evolved gas analysis by mass spectrometry. Appl Spectrosc Rev. 2014;49:635-65.

4. Papadopoulos C, Cristóvão B, Ferenc W, Hatzidimitriou A, Vecchio Ciprioti S, Risoluti R, Lalia-Kantouri M. Thermoanalytical, magnetic and structural investigation of neutral $\mathrm{Co}$ (II) complexes with 2,2'-dipyridylamine and salicylaldehydes. J Therm Anal Calorim. 2016;123:717-29.

5. Materazzi S, Risoluti R, Napoli A. EGA-MS study to characterize the thermally induced decomposition of $\mathrm{Co}$ (II), $\mathrm{Ni}$ (II), $\mathrm{Cu}$ (II) and $\mathrm{Zn}$ (II) complexes with 1,1-diaminobutane-Schiff base. Thermochim Acta. 2015;606:90-4.

6. Materazzi S, Finamore J, Risoluti R, Napoli A, D’Arienzo S. Characterization of thermally induced mechanisms by mass spectrometry-evolved gas analysis (EGA-MS): a study of divalent cobalt and zinc biomimetic complexes with $\mathrm{N}$-heterocyclic dicarboxylic ligands. Int J Mass Spectrom. 2014;365-366:372-6.

7. Materazzi S, Finamore J, Risoluti R, Napoli A. Biomimetic complexes of $\mathrm{Co}(\mathrm{II}), \mathrm{Cu}(\mathrm{II})$ and $\mathrm{Ni}(\mathrm{II})$ with 2-aminomethylbenzimidazole. EGA-MS characterization of the thermally induced decomposition. Microchem J. 2014;115:27-31.

8. Materazzi S, Foti C, Crea F, Risoluti R, Finamore J. Biomimetic complexes of divalent cobalt and zinc with $\mathrm{N}$-heterocyclic dicarboxylic ligands. Thermochim Acta. 2014;580:7-12.

9. Materazzi S, De Angelis Curtis S, Vecchio Ciprioti S, Risoluti R, Finamore J. Thermogravimetric characterization of dark chocolate. J Therm Anal Calorim. 2014;116:93-8.

10. Risoluti R, Gullifa G, Fabiano MA, Materazzi S. Biomimetic Complexes of $\mathrm{Co}(\mathrm{II}), \mathrm{Mn}(\mathrm{II})$, and $\mathrm{Ni}(\mathrm{II})$ with 2-Propyl-4,5-imidazoledicarboxylic Acid. EGA-MS Characterization of the Thermally Induced Decomposition. Russ J Gen Chem. 2015;85-10:2374-7.

11. Risoluti R, Fabiano MA, Gullifa G, Vecchio Ciprioti S, Materazzi S. FTIR-evolved gas analysis in recent thermoanalytical investigations. Appl Spectr Rev. 2017;52:39-72.
12. Risoluti R, Piazzese D, Napoli A, Materazzi S. Study of [2-(2'pyridyl)imidazole] complexes to confirm two main characteristic thermoanalytical behaviors of transition metal complexes based on imidazole derivatives. J Anal Appl Pyrolysis. 2016;117:82-7.

13. Materazzi S, Gregori A, Ripani L, Apriceno A, Risoluti R. Cocaine profiling: implementation of a predictive model by ATRFTIR coupled with chemometrics in forensic chemistry. Talanta. 2017;166:328-35.

14. Risoluti R, Materazzi S, Gregori A, Ripani L. Early detection of emerging street drugs by near infrared spectroscopy and chemometrics. Talanta. 2016;153:407-13.

15. Forina M, Casale M, Oliveri P. Application of chemometrics to food chemistry. Genoa: University of Genoa; 2009.

16. Garg V, Oberoi SS, Gorea RK, Kaur K. Changes in the levels of vitreous potassium with increasing time since death. J Ind Acad Forensic Med. 2004;26:136-9.

17. Arroyo A, Rosel P, Marron T. Cerebrospinal fluid: postmortem biochemical study. J Clin Forensic Med. 2005;12:153-6.

18. Coe JI. Postmortem chemistries on vitreous humour. Am J Pathol. 1969;51:741-50.

19. Coe JI. Vitreous potassium as a measure of the postmortem interval: an historical review and critical evaluation. Forensic Sci Int. 1989;42:201-13.

20. Coe JI, Apple FS. Variations in vitreous humour chemical values as a result of instrumentation. J Forensic Sci. 1985;30:828-35.

21. Madea B. Is there recent progress in the estimation of the post mortem interval by means of thanatochemistry? Forensic Sci Int. 2005;151:139-49.

22. Madea B, Käferstein H, Hermann N, Sticht G. Hypoxanthine in vitreous humour and cerebrospinal fluid: a marker of postmortem interval and prolonged (vital) hypoxia? Remarks also on hypoxanthine in SIDS. Forensic Sci Int. 1994;65:19-31.

23. Harper DR. A comparative study of the microbiological contamination of postmortem blood and vitreous humor samples taken for ethanol determination. Forensic Sci Int. 1989;43:37-44.

24. James RA, Hoadley PA, Sampson BG. Determination of postmortem interval by sampling vitreous humour. Am J Forensic Med Pathol. 1997;18:158-62.

25. Henssge C, Madea B. Estimation of the time since death. Forensic Sci Int. 2007;165:182-4.

26. Madea B. Methods for determining the time since death. For Sci Med Pathol. 2016;12:451-85.

27. Madea B. Estimation of the Time Since Death. 3rd ed. New York: CRC Press; 2016.

28. McLaughlin PS, McLaughlin BG. Chemical analysis of bovine and porcine vitreous humors: correlation of normal values with serum chemical values and changes with time and temperature. Am J Vet Res. 1987;48:467-73.

29. Schoning O, Strafuss AC. Determining time of death of a dog by analysing blood, cerebrospinal fluid and vitreous humour colected postmortem. Am J Vet Res. 1980;41:955-7.

30. Sturner WQ. The vitreous humour: postmortem potassium changes. Lancet. 1963;1:807-8.

31. Adjutantis G, Coutselinis A. Estimation of the time of death by potassium levels in the vitreous humour. Forensic Sci. 1972;1:55-60.

32. Madea B, Henssge BC, Honig W, Gerbracht A. References for determining the time of death by potassium in vitreous humor. Forensic Sci Int. 1989;40:231-43.

33. Munoz Barus JI, Suarez-Penaranda J, Otero XL, RodriguezCalvo MS, Costas E, Miguens X. Improved estimation of postmortem interval based on differential behaviour of vitreous potassium and hypoxantine in death by hanging. Forensic Sci Int. $2002 ; 125: 67-74$ 
34. Madea B, Lachenmeier DW. Postmortem diagnosis of hypertonic dehydration. Forensic Sci Int. 2005;155:1-6.

35. Madea B, Rodig A. Time of death dependent criteria in vitreous humor: accuracy of estimating the time since death. Forensic Sci Int. 2006;164:87-92.

36. Munoz JI, Costas E, Rodriguez-Calvo MS, Suarez-Penaranda JM, Lopez- Rivadulla M, Concheiro L. A high-performance liquid chromatography method for hypoxanthine determination in vitreous humour: application to estimation of post mortem interval. Hum Exp Toxicol. 2006;25:279-81.

37. Munoz-Barus JI, Rodriguez-Calvo MS, Suarez-Penaranda JM, Vieira DN, Cadarso-Suarez C, Febrero-Bande M. PMICALC: an $\mathrm{R}$ code-based software for estimating post-mortem interval (PMI) compatible with Windows, Mac and Linux operating systems. Forensic Sci Int. 2010;194:49-52.

38. Locci E, Scano P, Rosa MF, Nioi M, Noto A, Atzori L, Demontis R, De-Giorgio F, D'Aloja E. A Metabolomic approach to animal vitreous humor topographical composition: a pilot study. PLoS One. 2014;9(5):e97773.

39. Donaldson AE, Lamont L. Estimation of post-mortem interval using biochemical markers. Aust J Forensic Sci. 2014;46:8-26.

40. Patrick WJ, Logan RW. Free amino acid content of the vitreous humour in cot deaths. Arch Dis Child. 1988;63:660-2.

41. Croxtona RS, Barona MG, Butlerb D, Kentc T, Searsc VG. Variation in amino acid lipid composition of latent fingerprints. Forensic Sci Int. 2010;199:93-102.

42. Di Gioia ML, Leggio A, Liguori A, Perri F, Siciliano C, Viscomi MC. A preparation of N-Fmoc-N-methyl- $\alpha$-amino acids and $\mathrm{N}$-nosyl-N-methyl- $\alpha$-amino acids. Amino Acids. 2010;38(1): 133-43.

43. Aiello D, Materazzi S, Risoluti R, Thangavel H, Di Donna L, Mazzotti F, Casadonte F, Siciliano C, Sindona G, Napoli A. Major allergen in rainbow trout (Oncorhynchus mykiss): complete sequences of Parvalbumin by MALDI tandem mass spectrometry. Mol BioSyst. 2015;11(8):2373-82.
44. Di Gioia ML, Barattucci A, Bonaccorsi P, Leggio A, Minuti L, Romio E, Temperini A, Siciliano C. Deprotection/reprotection of the amino group in $\alpha$-amino acids and peptides. A one-pot procedure in $[\mathrm{Bmim}][\mathrm{BF} 4]$ ionic liquid, RSC. Advances. 2014;4(6): 2678-86.

45. Massart DL, Vandeginste BGM, Buydens LMC, De Jong S, Lewi PL, Smeyers-Verbeke J, Vandeginste BGM, Rutan SC, editors. Handbook of Chemometrics and Qualimetrics. Part B, 20B. Amsterdam: Elsevier; 1998. p. 88-103.

46. Massart DL, Vandeginste BGM, Buydens LMC, De Jong S, Lewi PL, Smeyers-Verbeke J, Vandeginste BGM, Rutan SC, editors. Handbook of Chemometrics and Qualimetrics. Part B, 20B. Amsterdam: Elsevier; 1998. p. 213-20.

47. Barnes RJ, Dhanoa MS, Lister SJ. Standard Normal Variate Transformation and De-trending of Near-Infrared Diffuse Reflectance Spectra. Appl Spectrosc. 1989;43:772-7.

48. Wold S, Sjöström M. SIMCA: a method for analyzing chemical data in terms of similarity and analogy. In: Kowalski BR, editor. Chemometrics: theory and applications. American chemical society symposium series, vol. 52. Washington: American Chemical Society; 1977. p. 243-82.

49. Savitzky A, Golay MJE. Smoothing and differentiation of data by simplified least squares procedures. Anal Chem. 1964;36: $1627-39$.

50. Forina M, Lanteri S, Armanino C, Casolino C, Casale C, Oliveri P. V-PARVUS. An extendable package of programs for explorative data analysis, classification and regression analysis. University of Genova, 2009, Free available at http://www.parvus. unige.it. 